\title{
RELATO TÉCNICO DA APURAÇÃO DE DIFAL EM SANTA CATARINA COM BASE NO CONVÊNIO 52/2017
}

\section{TECHNICAL REPORT OF THE DIFAL CLEARANCE IN SANTA CATARINA BASED ON THE CONVENTION 52/2017}

Recebido: 29/04/2019 - Aprovado: 10/06/2019 - Publicado: 01/07/2019 Processo de Avaliação: Double Blind Review
Gazielle Santos Oliveira ${ }^{1}$ Marcus Vinicius Moreira Zittei ${ }^{2}$ Michele Braga Dos Santos Silva ${ }^{3}$

\section{RESUMO}

Este artigo trata se de um relato técnico empírico descritivo que tem como objetivo verificar e esclarecer pontos polêmicos no que diz respeito a apuração e recolhimento do diferencial de alíquota (DIFAL) interestadual na filial de uma empresa multinacional, localizada em Santa Catarina. Para tanto foi necessário um estudo de legislações pertinentes ao exposto, como o Convênio 52 de 2017, Regulamento do ICMS de Santa Catarina de 2001 e outras, bem como reflexão acerca de cultura organizacional. Para implantação do plano de ação foi utilizado pesquisa qualitativa, ou seja, a relação entre o real e o conceitual não requer técnicas estatísticas para desenvolvimento e demonstração dos dados. Do ponto de vista dos procedimentos, este relato técnico será feito com base em pesquisa bibliográfica e documental. Após as pesquisas e o levantamento documental foram elaboradas algumas propostas que foram sugeridas a Empresa A (matriz), a fim de melhorar o procedimento como um todo na sua filial (Filial C). Entretanto, diante de um cenário de uma empresa com uma cultura organizacional enxuta, o processo de aceitação e implantação das propostas demorou, mas ainda assim, ocorreu.

Palavras-chave: DIFAL, Legislações, Cultura organizacional, Filial C.

\section{ABSTRACT}

This article deals with a descriptive empirical technical report that aims to verify and clarify controversial points regarding the calculation and collection of the interstate tax differential (DIFAL) in the branch of a multinational company located in Santa Catarina. To do so, it was necessary to study legislation relevant to the above, such as Convention 52 of 2017, ICMS Regulation of Santa Catarina 2001 and others, as well as reflection on organizational culture. For the implementation of the action plan, qualitative research was used, that is, the relationship between the real and the conceptual does not require statistical techniques for data development and demonstration. From the point of view of procedures, this technical report will be made based on bibliographical and documentary research. After the research and the documentary survey, some proposals were made that were suggested to Company A (matrix), in order to improve the procedure as a whole in its subsidiary (Subsidiary C). However, faced with a scenario of a company with a lean organizational culture, the process of acceptance and implementation of the proposals took time, but nevertheless, it occurred.

Key-words: Differentiation of rate, Legislation, Organizational culture, Subsidiary C

Especilista em Gestão Tributária, Contadora pela FECAP, São Paulo - SP, Brasil. E-mail: grazielles.oliveira@yahoo.com

${ }^{2}$ Doutor em Ciências Contábeis e Administração, Mestre em Ciências Contábeis, Contador, Professor. FMU, São Paulo/SP, Brasil. E-mail: marcuszittei@zittei.com.br

3 Mestranda em Governança Corporativa pela FMU, São Paulo/SP, Brasil. E-mail: michelebraga06@hotmail.com 


\section{INTRODUÇÃO}

Segundo Baratto e Macedo (2007) desde a sua instituição o Imposto Sobre Circulação de Mercadoria e Sobre Prestações de Serviço de Transporte Interestadual e Intermunicipal e de Comunicação (ICMS), assume a posição em primeiro lugar no ranking de arrecadação no Brasil. Sendo um tributo plurifásico, o mesmo passa por toda a cadeia, desde a produção até a distribuição, chegando ao contribuinte final.

Levando isto em consideração e todas as minúcias trazidas por este tributo, este Relato Técnico descreve um dos desdobramentos do ICMS: a apuração do Diferencial de Alíquota (DIFAL) de uma das filiais da Empresa A (matriz), localizada no estado de Santa Catariana. A Empresa A é uma multinacional localizada no estado de São Paulo.

Ao tratar de diferencial de alíquota, para Savi e Silva (2017), é uma forma de o governo ter maior adequação e distribuição do imposto para cada estado presente na operação. Em outras palavras, é o recolhimento da diferença da alíquota interna do estado de destino menos alíquota interestadual aplicado ao valor do item apurado para o estado de destino, assim um governo não arrecada mais que outro, devido a incentivos e/ou outros benefícios que o possibilite arrecadar mais impostos.

Desta forma, a cada nota fiscal emitida com destino à filial catarinense (aqui chamada de Filial C), traz anexada a obrigação de fazer uma análise prévia semanalmente, para verificar se os produtos adquiridos devem ter o recolhimento do Diferencial de Alíquota de acordo com o que foi estabelecido no Convênio 52/2017 e incorporado pelo Regulamento do ICMS Estado de Santa Catarina em seu Anexo 3, Artigo 21, parágrafo quarto, incisos I e II (sendo estes acrescidos pelo Decreto $\mathrm{n}^{\circ} 1.432 / 2017$, com efeitos a partir de 01.01.2018). Isto é, verificar se determinados produtos, com base nas NCM's (Nomenclatura Comum do Mercosul), devem ter seu recolhimento feito semanal ou mensalmente. Esta separação é feita previamente com base em uma análise simples, que consiste em verificar se é uma operação interestadual, se tem ICMS ST recolhido, se de fato é uma operação de venda de bens de uso e consumo ou ativo e por fim faz-se análise da NCM e se este tem substituição tributária ou não.

Perante tais casos, de acordo com Baratto e Macedo (2007), surgiram muitas críticas acerca do ICMS, gerando constantemente propostas para uma reforma tributária.

Diante do exposto, sobre o período de apuração, a semanal é a que tem maior representatividade e impacto no Cash Flow da Companhia, visto que a maioria das NCMs que são adquiridas para uso e consumo da filial C, estão presentes nos anexos do Convênio 52/2017. A mesma empresa também depara se com a questão do prazo para pagamento da guia emitida após a apuração do imposto, que é de sete dias a partir da data de emissão da nota fiscal. Outros pontos que impactam esta apuração, por exemplo, é a quantidade adquirida semanalmente de unidades de entrada como mouses e teclados, replicadores, computadores portáteis; a compra de utensílios de limpeza em outro estado, assim como a entrega da guia de recolhimento ao departamento financeiro da empresa para pagamento com até dois dias de antecedência do seu vencimento.

Para tanto aplicou se um modelo de ação em busca de legislações pertinentes ao ICMS com o objetivo de aprimorar a análise e questionar por que essa apuração de DIFAL vem sendo executada da mesma forma e porque nunca houve nenhuma discussão sobre possíveis formas de aprimoramento. Questionar se realmente é necessária essa separação de períodos, entre semanal e mensal; qual legislação trouxe de fato esta atribuição; se há alguma forma de diminuir as operações de compra interestaduais; qual a influência do Convênio 52/2017 nesta 
apuração; se de fato assumir as regras deste Convênio (e de outros relacionados) é constitucional.

\section{REFERENCIAL TEÓRICO}

\subsection{O ICMS E O DIFERENCIAL DE ALÍQUOTA}

Segundo Neves (2017, p. 18), a cronologia histórica do imposto sobre mercadorias é antiga, desde a época da colonização. Entretanto, na área legislatória, o Imposto Sobre Circulação de Mercadoria e Sobre Prestações de Serviço de Transporte Interestadual e Intermunicipal e de Comunicação (ICMS) iniciou-se por meio da Lei n ${ }^{\circ} 5.172$ de 1966 em seus arts. 52 a 58 do Código Tributário Nacional (CTN) que traz as primeiras normas gerais - revogadas logo em seguida pelo Decreto-lei $\mathrm{n}^{\circ} 406$ de 1968; em 1988 passa a fazer parte Constituição Federal (CF) e em 1996 é estabelecido pela Emenda Constitucional (EC) $n^{\circ} 87$.

Na Constituição Federal de 1988, art. 155, aborda em quais situações instituir-se-á o imposto e é no Inciso II deste mesmo artigo que a operação de compra de mercadorias para Filial C identifica-se. Isto é, "[...] operações relativas à circulação de mercadorias e sobre prestações de serviços de transporte interestadual e intermunicipal[...]”. (BRASIL, 1988)

Neves (2017) explica que, como regra geral, cada estado estabelece suas regras específicas por ser um imposto de âmbito estadual. Desta maneira, conta com 27 legislações diferentes, além do Distrito Federal. A alíquota estabelecida em cada estado é chamada de alíquota interna. Em uma venda interestadual essas alíquotas diferenciam-se uma da outra. Deste modo, com o objetivo de minimizar o impacto da desigualdade de alíquotas entre os estados, surge a Emenda Constitucional -EC n ${ }^{\circ}$ 87/96 que altera a forma de cobrança do imposto sobre as operações e prestação de bens e serviços para consumidor final (contribuinte ou não do imposto) estabelecido em outro Estado.

Contudo, para explicar o que é o Diferencial de Alíquota (DIFAL) e entender como este é feito na Filial C faz-se necessário compreender conceitos básicos: no art. 155, parágrafo $2^{\circ}$, da Constituição Federal, antevê três formas para incidência do ICMS nas operações e prestações interestadual, conforme Brasil Jr. (2016) apud Neves (2017):

\footnotetext{
a) Destinatário contribuinte do imposto, consumidor final;

b) Destinatário não contribuinte do imposto, não consumidor final (revendedor comercial ou industrial); e

c) Destinatário não contribuinte do imposto (consumidor final).
}

A situação aplicada a Filial C da Empresa A é a primeira situação, ou seja, é o quando o adquirente (Filial C) é contribuinte e consumidor final. Neste caso a arrecadação do ICMS é feita em duas etapas, uma por parte do remetente (estado de onde saiu a mercadoria $=$ estado de origem) e a outra por parte do destinatário (estado onde se recebe a mercadoria $=$ estado de destino = Santa Catarina). Portanto, no instante que o rementente libera as saídas de mercadorias são aplicadas as alíquotas interestaduais sobre as bases de cálculo das operações e o valor ali arrecadado é enviado ao estado de origem. Ao chegar em Santa Catarina, aplicase a diferença entre a alíquota interna do estado de destino e a alíquota interestadual, sendo esta diferença o que é chamado de Diferencial de Alíquota (DIFAL), o valor apurado desta diferença é pago ao estado catarinense (estado de destino). (BRASIL JR., 2016 apud NEVES, 2017) 
As alíquotas internas apresentadas na Tabela 1, seguem o Art. 26 da RICMS Regulamento do Imposto Sobre Circulação de Mercadoria e Sobre Prestações de Serviço de Transporte Interestadual e Intermunicipal e de Comunicação de Santa Catarina, após a análise de uma nota coletada aleatoriamente apenas para demonstração. (SANTA CATARINA, 2001)

Tabela 1: Cálculo de Diferencial de Alíquota em Santa Catarina

\begin{tabular}{lcccccc}
\hline \multicolumn{7}{c}{ APURAÇÃO DIFAL } \\
\hline Emitente/NF & $\begin{array}{c}\text { Data } \\
\text { emissão }\end{array}$ & $\begin{array}{c}\text { Alíquota } \\
\text { interna }\end{array}$ & $\begin{array}{c}\text { Alíquota } \\
\text { interestadual }\end{array}$ & $\begin{array}{c}\text { Alíquota a } \\
\text { Recolher }\end{array}$ & $\begin{array}{c}\text { Base de } \\
\text { Cálculo }\end{array}$ & $\begin{array}{c}\text { Valor } \\
\text { Apurado }\end{array}$ \\
\hline & $\mathbf{A}$ & $\mathbf{B}$ & $\mathbf{C}$ & $\mathbf{D}$ & $\mathbf{E}$ \\
\hline $\begin{array}{l}\text { Empresa X/ } \\
\text { Nota 1 }\end{array}$ & $01 / 06 / 2018$ & $17 \%$ & $12 \%$ & $5 \%$ & 615,20 & 30,76 \\
\hline Fonte:
\end{tabular}

Fonte: Elaborado pela Autora

Legenda:

$\mathrm{A}=$ Alíquota Interna

$\mathrm{B}=$ Alíquota Interestadual

$\mathrm{C}=$ Alíquota a recolher

$\mathrm{D}=$ Base de cálculo

$\mathrm{E}=$ Valor Apurado

Cálculo:

$\mathrm{A}-\mathrm{B}=\mathrm{C}$

$\mathrm{C} * \mathrm{D}=\mathrm{E}$

A forma apresentada na tabela, é a forma como vem sendo feito o cálculo do diferencial de alíquota desde de meados de 2017, tendo como base o Art. 9 do RICMS/SC em que determina qual será a base de cálculo nas operações, "a base de cálculo do imposto nas operações com mercadorias é [...] VII - na hipótese do art. $3^{\circ}$, XIV, o valor da operação no Estado de origem ou no Distrito Federal;

Já o cálculo em si, é mesmo feito com base no parágrafo 6 do Art. 3 do RICMS/SC em que diz o imposto deverá ser calculado por meio da utilização das fórmulas:

[...] ICMS origem $=$ BC x ALQ inter" e "ICMS destino $=[$ BC x ALQ intra $]-$ ICMS origem", em que:

I - "BC" é a base de cálculo do imposto, que é única e corresponde ao valor da operação, observado o disposto no art. 22;

II - "ALQ inter" é alíquota interestadual aplicável à operação;

III - "ALQ intra" é a alíquota interna aplicável à operação no Estado de destino.

\subsection{RICMS / SC E CONVÊNIO 52/2017}

Ao se falar de tributos, de modo geral, desperta a questão de valores a pagar, e de certa forma, assim o é. Tratar de tributos consequentemente é lidar com seu fato gerador, ou seja, é quando há o nascimento da obrigação jurídica de pagar determinado tributo. Tendo isto em vista, o Art. 3 do RICMS/SC traz também a questão do fato gerador na entrada de mercadoria de outra unidade federativa, fato importante para este Relato Técnico (SANTA CATARINA, 
2001), visto que esse é o ponto de partida para haver ou não a análise da nota fiscal e consequentemente a apuração do diferencial de alíquota - DIFAL:

Art. $3^{\circ}$ Considera-se ocorrido o fato gerador do imposto no momento:

$[\ldots]$

XIV - da entrada, no estabelecimento do contribuinte, de mercadoria oriunda de outro Estado ou do Distrito Federal, destinada a consumo ou ao ativo permanente.

Já o Parágrafo Primeiro da Cláusula Primeira do Convênio 52 de 2017 traz:

Cláusula Primeira Os convênios e protocolos celebrados pelas unidades federadas para fins de substituição tributária do Imposto sobre Operações Relativas à Circulação de Mercadorias e sobre Prestações de Serviços de Transporte Interestadual e Intermunicipal e de Comunicação (ICMS) devido nas operações subsequentes observarão o disposto neste convênio.

$\S 1^{\circ} \mathrm{O}$ disposto no caput aplica-se também ao imposto correspondente à diferença entre a alíquota interna da unidade federada de destino e a alíquota interestadual incidente sobre as operações interestaduais com bens e mercadorias destinadas ao uso, consumo ou ativo imobilizado do destinatário contribuinte do imposto.

Após identificar que existe o fato gerador conforme citado no Art. 9 do RICMS/SC, a cláusula primeira acompanhada do parágrafo primeiro traz o assunto principal deste relato técnico; o diferencial de alíquota, ou seja, " a diferença entre a alíquota interna da unidade federada de destino e a alíquota interestadual [...]”. (BRASIL,2017) Levando em consideração o Parágrafo Primeiro da Cláusula Sétima: "O regime de substituição tributária alcança somente os itens vinculados aos respectivos segmentos nos quais estão inserido" (BRASIL,2017) , pode-se dizer que, quando um bem ou mercadoria sujeita ao regime de substituição tributária é adquirida de outra unidade federativa (conhecido como operação interestadual), é destinada ao uso e consumo ou a integração do ativo imobilizado de uma empresa, também é devido o diferencial de alíquota na entrada da mercadoria no estado (operação). Todavia, quando um bem ou mercadoria não é sujeito a substituição tributária e é adquirida para uso, consumo ou para integrar o ativo imobilizado da empresa, o diferencial de alíquota será calculado e devidamente recolhido juntamente com a apuração de ICMS, conforme Art. 53, § 6 (apuração). Em outras palavras, se o NCM desse bem ou mercadoria estiver nos Anexos II ao XXVI do Convênio 52/17, significa que esta mercadoria terá seu recolhimento feito por operação, ou popularmente chamado de semanal, pois é sujeita a substituição tributária. Caso contrário, terá seu recolhimento feito por puração, popularmente chamado de mensal. (SANTA CATARINA, 2001 e BRASIL, 2017)

Um dos pontos polêmicos deste relato é o fato de haver duas maneiras de recolhimento, conforme citado nos parágrafos anteriores. Entretanto, esta forma de recolhimento está prevista em lei, conforme Art. 21 do ANEXO III do RICMS/SC (SANTA CATARINA, 2001):

Art. 21. O imposto devido por substituição tributária deverá ser recolhido: I - em se tratando de sujeito passivo por substituição inscrito no cadastro de contribuinte do ICMS deste Estado, até o $10^{\circ}$ (décimo) dia do mês subsequente ao da saída do bem ou mercadoria;

II - em se tratando de sujeito passivo por substituição não inscrito no cadastro de contribuinte do ICMS deste Estado, por ocasião da saída do bem ou mercadoria do estabelecimento remetente, caso em que o transporte deverá ser acompanhado por uma das vias da GNRE ou DARE; e

$[\ldots]$ 
$\S 4^{\circ}$ Nas hipóteses previstas neste artigo, caso o contribuinte substituído receba mercadorias sujeitas à substituição tributária acobertadas por documento fiscal desacompanhado da GNRE ou DARE-SC, deverá:

[...]

II - recolher o imposto relativo a cada operação até o $7^{\circ}$ (sétimo) dia subsequente ao da emissão do documento fiscal.

Deste modo, observa se a legislação que instituiu tais atribuições e recolhimentos por tipos de apuração, afirmando assim, que ambas normativas atuam em conjunto.

\subsection{CULTURA ORGANIZACIONAL}

Segundo Rosini, Foresto e Palmisano (2015), há condições e particularidades culturais entre as organizações, estas derivadas de particularidades culturais de cada indivíduo que compõe uma organização, e é essa miscigenação que tem alterado a forma como as grandes companhias têm se estabelecido em um mercado demasiadamente concorrido.

De acordo com Macêdo (2002) apud Rosini, Foresto e Palmisano (2015), "a cultura é adquirida pelo ser humano por meio de mudanças de um grupo social que passa a ter contato com outra, ou seja, aprende valores e costumes no meio ao qual está inserido". Em outras palavras, a fim de estabelecer regras e assegurar que culturas individuais não sobreponham se outras em um ambiente corporativo, as companhias inserem seus colaboradores em seus princípios, valores e objetivos. Deste modo, as pessoas vivem uma única cultura dentro da organização.

Conforme Kotter (1992) apud Reginato (2010) “As pessoas são formadoras da cultura da empresa. [...] O fato é que a cultura, proveniente dos comportamentos das pessoas, pode ser um fator influente sobre a gestão dos ambientes externo e interno, [...] ". Em outras palavras e com base em outros estudos feitos por Moos (1979) apud Reginato (2010), a cultura organizacional de uma empresa, até certo ponto, é capaz de provocar, direta ou indiretamente, o desempenho da companhia.

A Empresa A, é uma grande incorporadora, e junto com suas incorporações são inseridos dentro da companhia novos procedimentos, novas formas de fazer, novas entregas, novos prazos, nova cultura organizacional, etc. Isso demanda uma adequação e remanejamento de pessoal, bem como uma reavaliação processual. O não cumprimento destes procedimentos impacta direta ou indiretamente em processos diários e futuros.

\section{METODOLOGIA}

Refere-se a um relato técnico empírico descritivo. Empírico por se tratar de uma experiência observada e vivenciada pela autora (MARTINS, 2002 APUD ROSINI, FORESTO E PALMISANO, 2015). Descritivo, pois traz características de determinada população ou estabelecimento com suas variáveis. (GIL, 1991 apud Da Silva e Menezes, 2005).

Para implantação do plano de ação será utilizado pesquisa qualitativa, ou seja, a relação entre o real e o conceitual não requer técnicas estatísticas para desenvolvimento e demonstração dos dados. Do ponto de vista dos procedimentos, este relato técnico será feito 
com base em pesquisa bibliográfica e documental. Bibliográfica, pois tem como base material já publicado como livros, periódicos e artigos. Documental, pois trata se de materiais gerenciais elaborados sem tratamento analítico. (GIL, 1991 apud DA SILVA E MENEZES, 2005).

Para implantação do plano de ação utilizar-se-á das seguintes simulações:

- Apuração de Diferencial de Alíquota Semanal (Abril a Junho);

- Apuração de Diferencial de Alíquota Mensal (Abril a Junho);

- Relatório Secretaria da Fazenda de SC Mensal (Abril a Junho);

- Apuração de Diferencial de Alíquota Semanal (Julho a Setembro);

- Apuração de Diferencial de Alíquota Mensal (Julho a Setembro);

- Relatório Secretaria da Fazenda de SC Mensal (Julho a Setembro);

- Realização de testes e simulados;

- Elaboração de gráficos.

\subsection{PERCURSSO METODOLÓGICO - SITUAÇÃO FILIAL C}

Com base em um dado empírico descritivo, fez se o seguinte levantamento com relação aos dados observados a partir da atividade de análise de notas para apuração do diferencial de alíquota do Segundo Trimestre de 2018 (Abril a Junho), conforme a tabela 2 e a figura 1:

Tabela 2: Classificação das Notas Recebidas no Segundo Trimestre de 2018

\begin{tabular}{lcc}
\hline \multicolumn{1}{c}{ Classificação } & Quantidade (un.) & $\%$ \\
\hline Diferencial de Alíquota recolhido por Operação (Semanal) & 85 & $45,5 \%$ \\
Diferencial de Alíquota recolhido por Apuração (Mensal) & 37 & $19,8 \%$ \\
Operação Interna (SC x SC) & 26 & $13,9 \%$ \\
NF de Remessa (Comodato, Locação, S. Garantia) & 16 & $8,6 \%$ \\
ICMS ST recolhido pelo emitente & 16 & $8,6 \%$ \\
NF Cancelada & 3 & $1,6 \%$ \\
NF de Prestação de Serviço. & 3 & $1,6 \%$ \\
Devolução de Mercadoria & 1 & $0,5 \%$ \\
\hline Total & 187 & $100 \%$ \\
\hline
\end{tabular}

Fonte: Elaborado pela Autora 


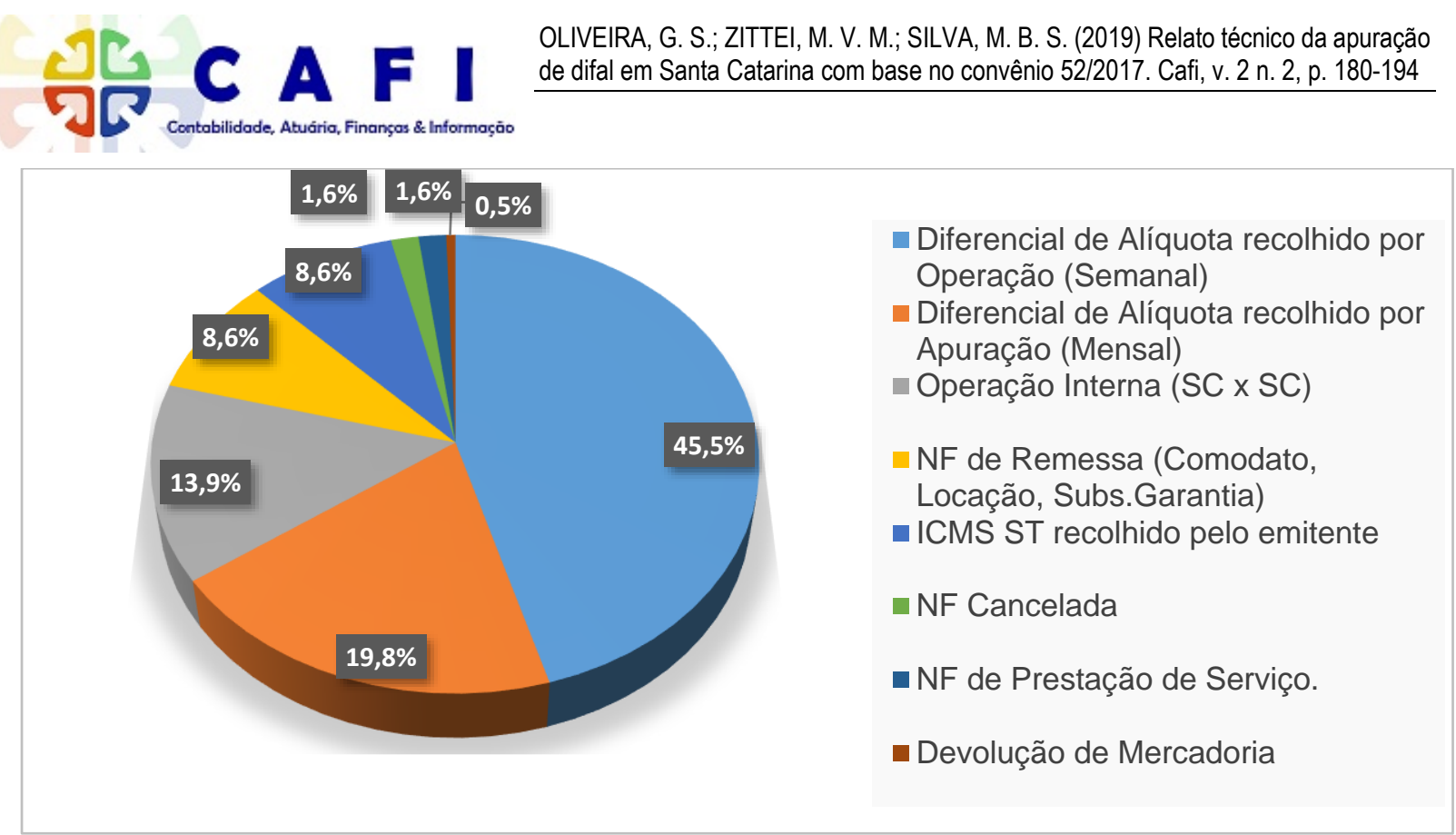

Figura 1: Classificação das Notas Recebidas no Segundo Trimestre de 2018

Fonte: Elaborado pela Autora

Com base nos dados apresentados, percebe se que aproximadamente $46 \%$ das notas recebidas pela Filial C são notas que tiveram diferencial de alíquota semanal recolhido e que aproximadamente $20 \%$ destas notas tiveram que ser revistas para análise e apuração mensal. As demais, que tem sua representatividade de $34 \%$, são notas que podem ser analisadas tanto semanal quanto mensalmente, ou até mesmo em ambas as situações, mas que não impactam financeiramente a Filial C. Impacta somente em relação ao tempo gasto para a devida análise do documento. Em outras palavras, isto demonstra a representatividade das notas que tem obrigatoriedade em recolhimento do diferencial de alíquota semanal diante às demais, bem como, o retrabalho em revisar todas as notas ao fim do mês e o gasto com mão-de-obra de terceiros.

A fim de demonstrar de forma quantitativa, demonstra se, na mesma linha empírica descritiva, os dados observados da apuração semanal do Segundo Trimestre de 2018, onde é demonstrado o valor apurado semanalmente, conforme a figura 2: 


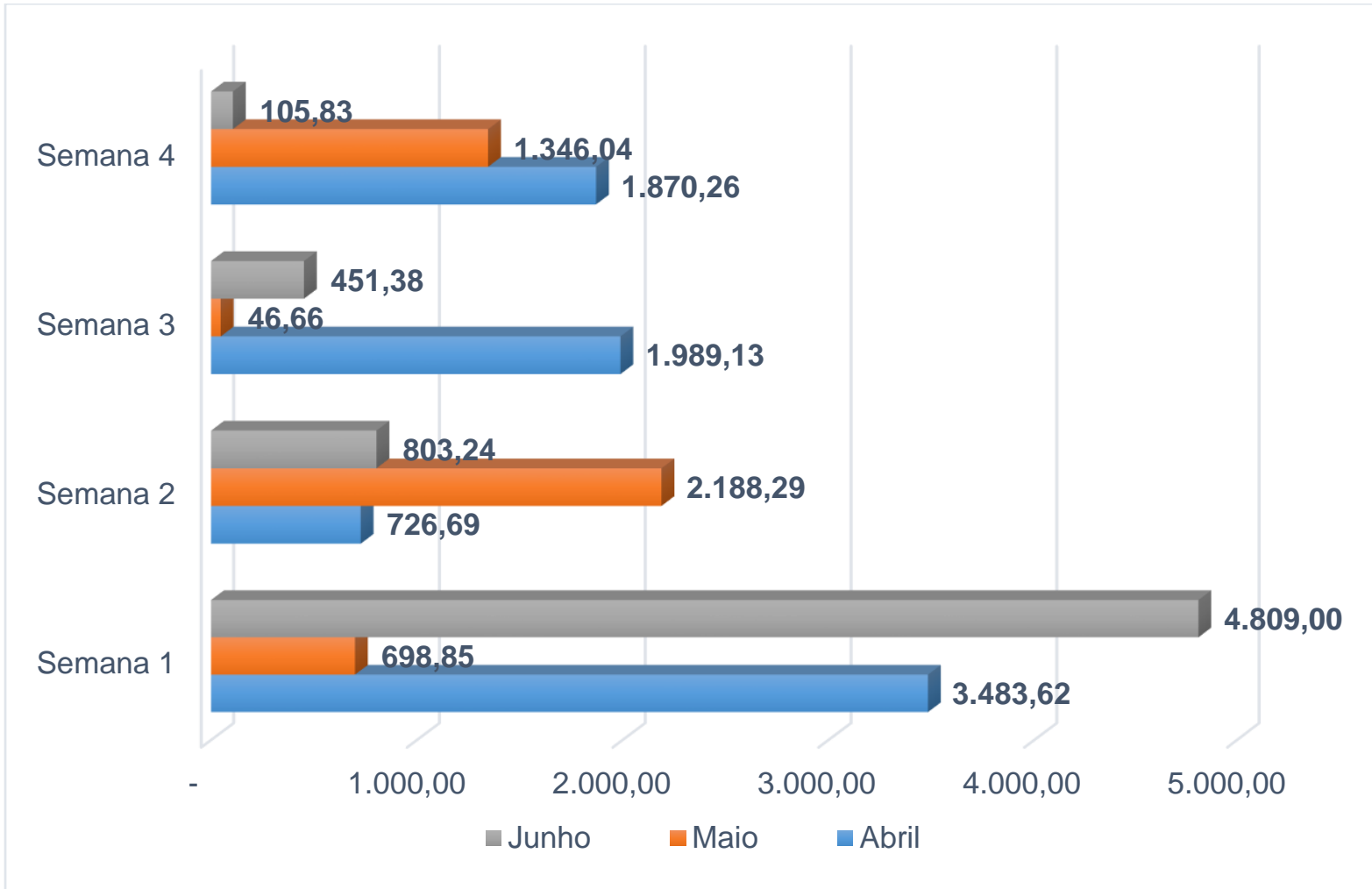

Figura 2: Representação da apuração semanal do DIFAL Semanal- $2^{\circ}$ trimestre Fonte: Elaborado pela Autora

Percebe se que no decorrer dos meses, a quantidade de notas com obrigatoriedade de apuração semanal diminui. Entretanto, isso varia de mês para mês e de semana para semana. Levando em consideração a figura 2, pode-se perceber um volume elevado na Semana 1 nos meses de Abril e Junho, todavia a semana com maior volume de notas para o mês de Maio foi a Semana 2.

Ao gerenciar uma empresa é necessário ter controles, levando em consideração que "estudos sob a abordagem contingente revelam a existência de impactos que as empresas sofrem no ambiente em que estão inseridas, mais especificamente nos tipos de controles gerenciais." (REGINATO, 2010)

Neste sentido, conforme Reginato (2010), as empresas convivem com dois ambientes:

- $\quad$ Um em que ele tem pouco controle e/ou quase nenhum, pois são ambientes imprevisíveis, como por exemplo, economia, política e outras;

- $\quad$ Outro ambiente é aquele onde as variáveis e ações são previsíveis e que a empresa consiga ter alguma influência no processo, como por exemplo, clientes, fornecedores e outros.

Ao tratar de notas emitidas por fornecedores, a Filial C consegue ter uma influência positiva se tiver controles gerenciais próprios para as funções necessárias.

A Filial C, por menor que sejam os valores a serem pagos semanalmente, está sendo impactada financeira e operacionalmente, pois, o fato de não saber o valor exato a ser pago semanalmente pode trazer riscos a Empresa A (que é a quem faz o gerenciamento dos pagamentos de todas as filiais). 


\section{RESULTADOS}

A Filial C faz operações de compras interestaduais de equipamentos eletrônicos e de telecomunicação com grande frequência, sendo estes produtos solicitados em pequena quantidade e periodicamente, em sua maioria para uso e consumo, mas também para ativo imobilizado. Isto impacta na situação problema, visto que, em sua maioria, são produtos com NCMs presentes no Convênio 52/2017. Em outras palavras, são produtos com substituição tributária adquiridas de outro estado e que deve ter seu DIFAL recolhido semanalmente.

Com base nisso, foi apresentado a Empresa A propostas , por meio da tabela 3 que a princípio melhorassem o fluxo de pedidos para Filial C, o que consequentemente melhoraria o fluxo de pagamentos e tempo gasto com mão-de-obra para apuração semanal do DIFAL.

Tabela 3: Propostas

1) Redução de pedidos faturados para Filial C: transferir a quantidade de pedidos a serem faturados semanalmente para um único período do mês, com isto haverá redução de notas a serem analisadas e apuradas semanalmente;

2) Controle gerencial: criar um controle gerencial para lidar com a quantidade de notas faturadas, com mão-de-obra gasta e com o valor apurado semanalmente que não tem como ser mensurado antes da apuração (por operação) de fato;

3) Encerrar a Filial C: com o encerramento da inscrição estadual da Filial C, a empresa deixará de ser obrigada e recolher o ICMS Difal, bem como deixar de entregar algumas obrigações acessórias do estado de Santa Catarina, como a DIME, por exemplo.

Observações*: As propostas acima foram retiradas de um documento interno e estabelecido entre as duas empresas (que por motivos de segurança não pode ser demonstrado na íntegra) e foi adaptado para este relato técnico.

Fonte: elaborada pela autora.

Observações diárias feitas com base no que foi apresentado, a Empresa A possui uma cultura organizacional bem enxuta com pouca flexibilidade; os colaboradores mais antigos não se permitem a grandes mudanças, a sugestões de melhoria tão facilmente; há dificuldades de convivência com colaboradores de empresas incorporadas e com colaboradores de empresas terceirizadas.

Mediante tal situação, foi solicitado uma nova reunião para demonstrar com mais detalhes o intuito das propostas as quais foram aceitas propostas por um trimestre na condição de teste. A seguir, na tabela 4 , seguem os dados observados pela autora - em termos de proporção com a quantidade de notas do período apurado - referente ao Terceiro Trimestre de 2018 (Julho a Setembro) de 2018 da Filial C: 
Tabela 4: Classificação das Notas Recebidas no Segundo Trimestre de 2018

\begin{tabular}{|c|c|c|}
\hline Classificação & $\begin{array}{l}\text { Quantidade } \\
\text { (un.) }\end{array}$ & $\%$ \\
\hline Diferencial de Alíquota recolhido por Operação (Semanal) & 31 & $29,8 \%$ \\
\hline Diferencial de Alíquota recolhido por Apuração (Mensal) & 26 & $25,0 \%$ \\
\hline Operação Interna (SC x SC) & 18 & $17,3 \%$ \\
\hline ICMS ST recolhido pelo emitente & 12 & $11,5 \%$ \\
\hline NF de Remessa (Comodato, Locação, Subs. Garantia) & 8 & $7,7 \%$ \\
\hline NF Cancelada & 3 & $2,9 \%$ \\
\hline NF de Prestação de Serviço. & 3 & $2,9 \%$ \\
\hline Devolução de Mercadoria & 3 & $2,9 \%$ \\
\hline Total & 104 & $100 \%$ \\
\hline
\end{tabular}

Fonte: Elaborado pela Autora

Pode-se observar na figura 3, em comparação a figura 1, em termos de proporção de quantidade e análise direta das notas analisadas, que houve uma queda de 15,7\% com relação as notas que apresentam NCMs com obrigatoriedade de apuração semanal, visto que no Segundo Trimestre 45,5\% das notas analisadas apresentavam recolhimento semanal e no Terceiro Trimestre conta-se com 29,8\% destas. Por sua vez, houve um aumento de 5,2\% para as notas com recolhimento de diferencial de alíquota mensal, levando em consideração que no período apurado anteriormente contava-se com 19,8\% das notas analisadas e para este período conta-se com $25 \%$. Houve também um pequeno aumento nas operações internas de $3,4 \%$. As demais classificações, como ICMS ST recolhido pelo emitente teve um aumento de $8,6 \%$ para $11,5 \%$; notas fiscais canceladas e de prestação de serviço tiveram um aumento de $1,6 \%$ para $2,9 \%$ e a devolução de mercadoria que teve um aumento de $0,5 \%$ para $2,9 \%$. 


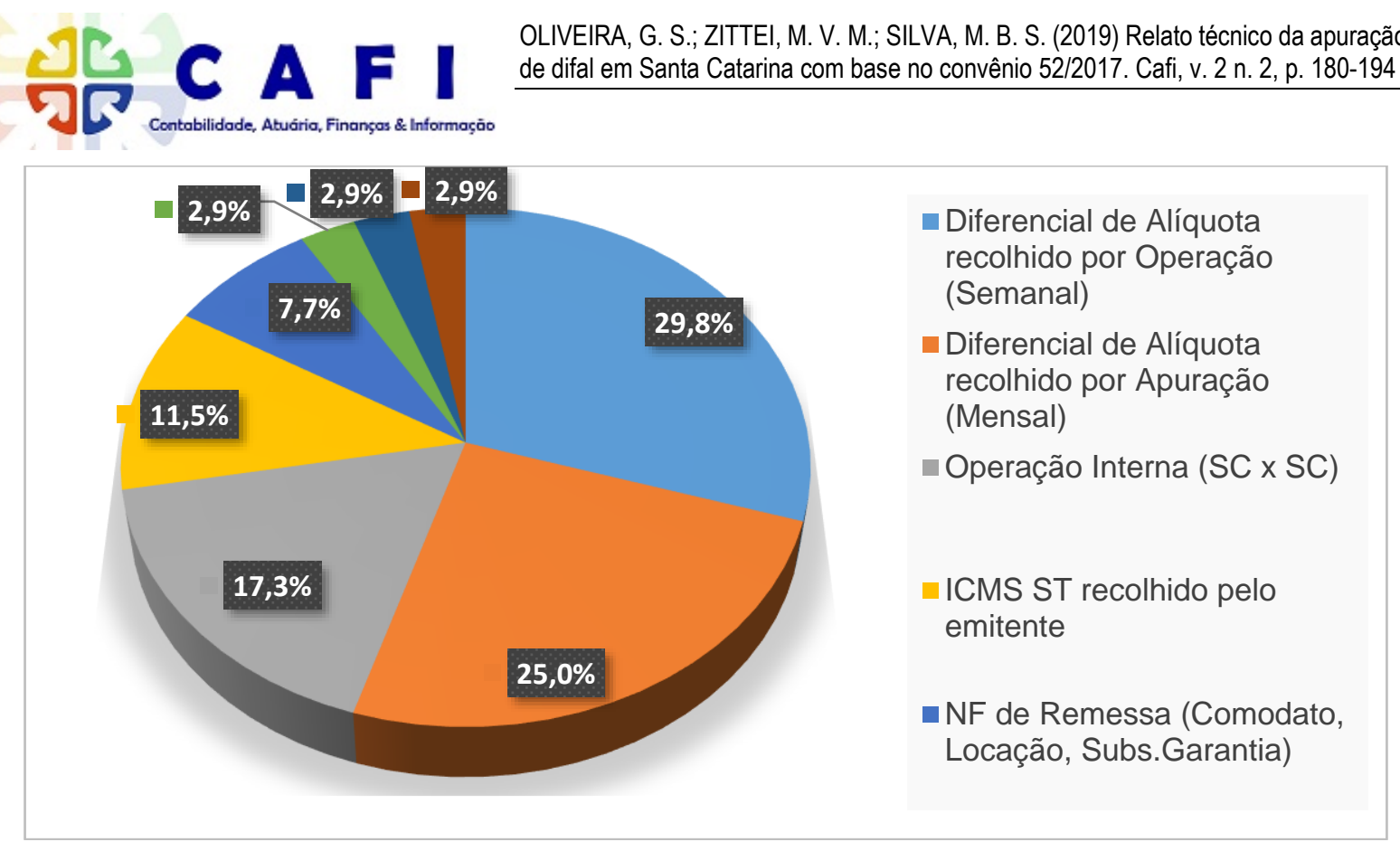

Figura 3: Classificação das Notas Recebidas no $3^{\circ}$ Trimestre de 2018

Fonte: Elaborado pela Autora

Na tabela 5 há uma análise feita com base na observação nas notas recebidas, em que nota-se uma queda de aproximadamente $44 \%$ no recebimento de notas de um trimestre para outro:

Tabela 5: Comparativo da Quantidade de Notas Recebidas no $2^{\circ}$ e $3^{\circ}$ Trimestres de 2018

\begin{tabular}{lcc}
\multicolumn{1}{c}{ Classificação } & 2 trim & $\mathbf{3}$ trim \\
\hline Diferencial de Alíquota recolhido por Operação (Semanal) & 85 & 31 \\
Diferencial de Alíquota recolhido por Apuração (Mensal) & 37 & 26 \\
Operação Interna (SC x SC) & 26 & 18 \\
ICMS ST recolhido pelo emitente & 16 & 12 \\
NF de Remessa (Comodato, Locação, Subs. Garantia) & 16 & 8 \\
NF Cancelada & 3 & 3 \\
NF de Prestação de Serviço. & 3 & 3 \\
Devolução de Mercadoria & 1 & 104 \\
\hline
\end{tabular}

Fonte: Elaborado pela Autora

A queda que apresenta maior representatividade, para a empresa e para este relato técnico, são as notas com NCMs que precisam ter seus respectivos diferenciais de alíquota recolhidos semanalmente. A figura 4 representa em termos quantitativos as variações do segundo trimestre para o terceiro trimestre demostrada na Figura 4: 


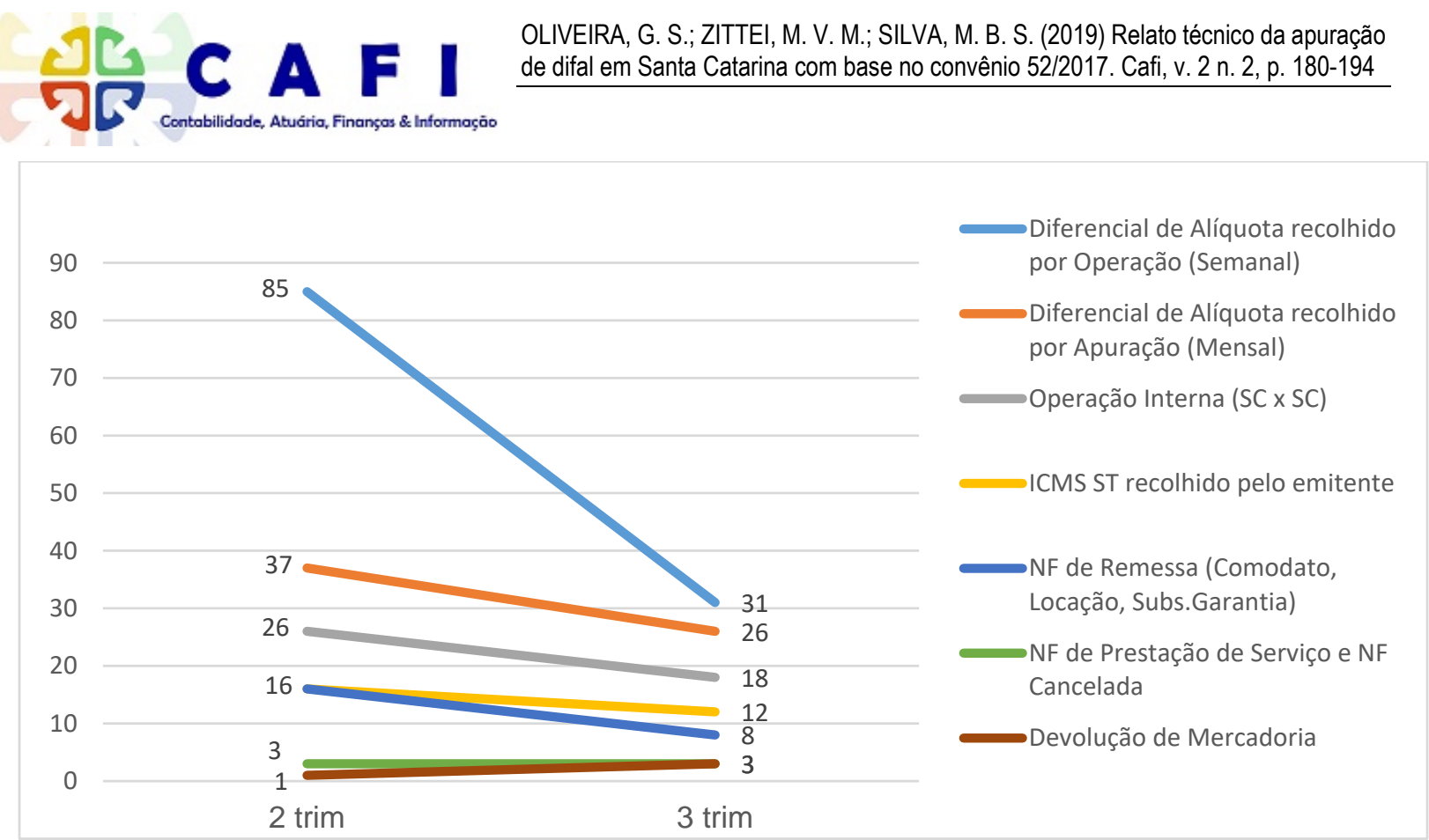

Figura 4: Comparativo da Quantidade de Notas Recebidas no $2^{\circ}$ e $3^{\circ}$ Trimestres de 2018 Fonte: Elaborado pela Autora

\section{CONSIDERAÇÕES FINAIS}

O objetivo principal deste relato técnico foi verificar e aprimorar a análise de apuração do diferencial de alíquota, visto que desde meados de 2017 nunca havia sido questionado a necessidade das apurações serem feitas semanal e mensamente, bem como, qual legislação trazia de fato esta atribuição; se havia alguma forma de diminuir as operações de compra interestaduais; qual era a influência do Convênio 52/2017 nestas apurações. Tendo como situação problema a divisão das apurações entre semanal e mensal; bem como a quantidade de notas emitidas para Filial $\mathrm{C}$ semanalmente, tendo que fazer seu recolhimento do diferencial de alíquota dos produtos que eram sujeitos a substituição tributária no sétimo dia útil e antecipar dois dias para poder enviar para central de pagamentos da Empresa A - que faz o gerenciamento de todos os pagamentos.

Para atingir os objetivos estabelecidos neste relato técnico foi necessário estudo do Convênio 52 de 2017 e por se tratar de Convênio faz-se necessário explicar que os convênios são maneiras que os governos encontraram para unificar e regulamentar todos os estados que o assume com relação ao ICMS, para que um estado não seja mais beneficiado que outro por causa de seus incentivos.

Deste modo, entende-se que a essência de sua influência está aí. Em conjunto com o Regulamento do Imposto Sobre Circulação de Mercadoria e Sobre Prestações de Serviço de Transporte Interestadual e Intermunicipal e de Comunicação de Santa Catarina, o RICMS/SC de 2001 que traz todos os seus conceitos e regulamentações pertinentes aos estados de Santa Catarina em comum acordo com as regras estabelecidas pelos convênios. Assim como, sobre cultura organizacional para entender determinados aspectos e processos da empresa que deixavam enrijecidas as mudanças necessárias para a apuração de diferencial de alíquota anteriormente. 
Mediante aos problemas apresentados neste relato, e a soluções apresentadas a Empresa A por meio das propostas, a Filial C apresentou uma diminuição nas notas recebidas, tanto nas notas que têm obrigatoriedade de recolhimento semanal, quanto nas demais.

Após o período de teste, estabelecido em um trimestre, a empresa continuou adotando as recomendações feitas, de Setembro até a primeira semana de Novembro a empresa apresentou:

- $\quad$ Melhor fluxo de recebimento;

- $\quad$ A quantidade de notas emitidas para Filial C continua diminuindo;

- Um dos colaboradores da Empresa A informou que até meados Janeiro é possível que a Filial $\mathrm{C}$ tenha sua inscrição estadual encerrada;

- $\quad$ Até mesmo a comunicação entre as equipes melhorou.

Isso demonstra que as proposta e recomendações sugeridas à Filial $\mathrm{C}$ foram aceitas e aplicadas apesar da cultura organizacional da empresa não ser tão aberta.

Ao tratar de cultura organizacional, identificou se dificuldades para pesquisas que abordassem temas em conjunto sobre Cultura Organizacional e Gestão Tributária e seus impactos diretos. Há pesquisas em outras nações, mas há a necessidade de um olhar crítico brasileiro sobre o tema. Portanto, sugere se tais quesitos para pesquisas futuras.

\section{REFERÊNCIAS}

Baratto, Gedalva; Macedo, Mariano de Mattos. (2011). Regime tributário do ICMS nas transações interestaduais-harmonização tributária ou autonomia estadual? Revista Paranaense de Desenvolvimento-RPD, n. 113, p. 09-30.

Brasil. (1988). Constituição da República Federativa do Brasil de 5 de out. de 1988. Seção IV Art. 155 Brasília, DF, out. 1988. Recuperado em 23/08/2018: <http://www.planalto.gov.br/ccivil_03/constituicao/Constituicao.htm> .

Brasil. (2017). Convênio N. 52/2017. Recuperado em 15/08/2018: < https://www.confaz.fazenda.gov.br/legislacao/convenios/2017/CV052_17> .

Brasil. (1968). Decreto-lei N. 406/1968. Recuperado em 23/08/2018: <http://www.planalto.gov.br/ccivil_03/Decreto-Lei/Del0406.htm\#art14> .

Brasil. (2017). Decreto N. 1.432/2017. Recuperado em 15/08/2018: <http://legislacao.sef.sc.gov.br/html/decretos/2017/dec_17_1432.htm>.

Brasil. (2015). Emenda Constitucional N. 87/2015. Recuperado em 23/08/2018: http://www.planalto.gov.br/ccivil_03/constituicao/Emendas/Emc/emc87.htm.

Brasil. (1996). Lei Complementar N. 87/1996. Recuperado em 23/08/2018: http://www.planalto.gov.br/ccivil_03/LEIS/LCP/Lcp87.htm.

Brasil. (1966). Lei N. 5.172/1966. Recuperado em 23/08/2018: <http://www.planalto.gov.br/ccivil_03/LEIS/L5172.htm> . 
Silva, Edna Lúcia da; Menezes, Estera Muszkat. (2005). Metodologia da pesquisa e elaboração de dissertação. UFSC, Florianópolis, 4a. edição, v. 123.Recuperado em 03/09/2018:

<https://projetos.inf.ufsc.br/arquivos/Metodologia_de_pesquisa_e_elaboracao_de_teses_e_disser tacoes_4ed.pdf>

Neves, Marielli Cardoso das. (2017). Impacto do diferencial de alíquota (DIFA) nas prestações de serviços de transportes interestaduais de cargas para consumidor final não contribuinte do ICMS. Criciúma SC. 2017. Recuperado em 06/08/2018: $<$ http://repositorio.unesc.net/handle/1/5441 > .

Reginato, L. (2011). Um estudo setorial sobre as relações entre variáveis ambientais externas, modelos de gestão, controles gerenciais e desempenhos das empresas. 2010. Tese de Doutorado. Universidade de São Paulo. Recuperado em 11/10/2018: <http://www.teses.usp.br/teses/disponiveis/12/12136/tde-15042010-132200/en.php>.

Rosini, A. M.; Foresto, A. M.; Palmisano, (2015). A. Integração tecnológica e governança corporativa: relato técnico da aquisição entre dois bancos privados. Revista Capital Científico - Eletrônica, v. 13, n. 2, p. 112-123. Recuperado em 03/09/2018: <http://www.spell.org.br/documentos/ver/39071/integracao-tecnologica-e-governacacoporativa--relato-tecnico-da-aquisicao-entre-dois-bancos-privados/i/pt-br> .

Santa Catarina (Estado). (2001). Decreto 2.870 de 27 ago. de 2001. Aprova o Regulamento do ICMS do Estado de Santa Catarina. Recuperado em 15/08/2018 de < http://legislacao.sef.sc.gov.br/cabecalhos/frame_ricms_01_00_00.htm>.

Savi, André Luis; da Silva, Itacir Alves. (2017). Diferencial De Alíquota De ICMS. Revista Global Manager Acadêmica, v.6, n. 2, p. 402-41, 2017. Recuperado em 06/08.2018 de < http://ojs.fsg.br/index.php/globalacademica/article/view/3263 >. 